\title{
.
}

Susana Campuzano Fernández*

Pilar Vega Vicente**

\section{RIESGOS Y OPORTUNIDADES DE LA INTELIGENCIA ARTIFICIAL DESDE LA PERSPECTIVA DE LA COMPETENCIA Un análisis desde la CNMC}

La utilización de inteligencia artificial y algoritmos es cada vez más intensiva en todos los sectores. La defensa de la competencia no resulta ajena a los nuevos tipos de comportamientos anticompetitivos que de esta nueva realidad se derivan, ni, por otro lado, las autoridades de competencia deben quedar al margen de la aplicación de estas técnicas para la mayor eficiencia del cumplimiento de las competencias que tiene asignadas.

El presente trabajo aborda ambas cuestiones, desde la perspectiva y la experiencia reciente de la CNMC, estructurándose, en primer lugar, con una aproximación a los conceptos que se tratarán en el artículo, para continuar con los riesgos y beneficios que estas nuevas herramientas conllevan para la autoridad de competencia.

Palabras clave: bid rigging, colusión, algoritmo, colusión algorítmica.

Clasificación JEL: C40, C60, H83, L41.

\section{Introducción}

«Artificial Intelligence is likely to be the best or worst thing to happen to humanity».

StEPHEN HAWKING

Resulta complicado hoy en día no encontrar referencias a conceptos como inteligencia

\footnotetext{
* Jefa de la Unidad de Inteligencia Económica. Dirección de Competencia. Comisión Nacional de los Mercados y la Competencia.

** Subdirectora Adjunta de la Unidad de Inteligencia Económica. Dirección de Competencia. Comisión Nacional de los Mercados y la Competencia.

Las opiniones expresadas en el presente artículo son de exclusiva responsabilidad de las autoras y no necesariamente representan la posición de la CNMC, salvo expresamente indicado.

Versión de junio de 2021.

DOI: https:/doi.org/10.32796/bice.2021.3137.7259
}

artificial (IA) o algoritmos prácticamente en cualquier área de nuestra vida cotidiana. Estos conceptos, hasta hace unos años limitados a sectores más técnicos, se incluyen ahora con naturalidad en la vida diaria de empresas y ciudadanos.

Pese a que la inteligencia artificial en sus desarrollos más primarios encuentra sus orígenes hace varias décadas, lo cierto es que es en la actualidad cuando se plasma de manera más notoria su presencia e implementación a gran escala y, con ello, los beneficios - y también perjuicios- de sus aplicaciones.

El ámbito de las Administraciones públicas, y más concretamente de defensa de la $D$ 
competencia, no puede ni debe quedar al margen de todos estos desarrollos, y así se observa una tendencia internacional a la creación de unidades ad hoc encargadas de potenciar tanto la detección de oficio a través de la aplicación de estas técnicas como de analizar los riesgos que se derivan de la presencia de este tipo de sistemas en las empresas.

Entre estos riesgos nos encontramos cómo la inteligencia artificial puede dar lugar a la aparición de nuevas barreras de entrada, como las generadas por el acceso a datos, y señaladamente el uso de algoritmos puede derivar en comportamientos anticompetitivos como la colusión algorítmica.

Sin embargo, estas herramientas también pueden suponer una oportunidad para las autoridades de competencia, permitiendo entre otras cuestiones realizar una apuesta decidida por una detección de oficio, en particular con un importante impulso a la detección de casos de bid rigging o colusión en contratación pública. Cuestiones tales como el análisis de datos masivo, la automatización de tareas a través de algoritmos y la extracción y tratamiento de información a través de técnicas de machine learning pueden ser instrumentos de una alta utilidad para las autoridades de competencia, que han de adaptar sus organigramas y el perfil de su personal a estas nuevas realidades para avanzar de manera acorde a la sociedad.

El presente artículo realiza, en primer lugar, una somera aproximación a los orígenes y definiciones básicas relacionadas con la inteligencia artificial de términos que se utilizarán a lo largo del artículo. A continuación, el apartado tercero realiza una descripción de los principales riesgos que la presencia de estos nuevos desarrollos puede conllevar para con la competencia. Por último, el apartado cuarto se acerca al modo en que la Comisión Nacional de los
Mercados y la Competencia (CNMC) ha abordado este fenómeno, de manera particular a través de la creación de la Unidad de Inteligencia Económica de la Dirección de Competencia, señalando, así mismo, las principales técnicas utilizadas por esta en la detección de ilícitos.

\section{Inteligencia artificial. Orígenes y conceptos}

La utilización de conceptos como inteligencia artificial, algoritmos o machine learning, lejos de circunscribirse a ámbitos técnicos o de alta especialización, ha pasado en los últimos años a ser una referencia constante y normalizada en los discursos cotidianos de la práctica totalidad de los sectores y la ciudadanía. Sin embargo, y pese a que pudieran parecer desarrollos hasta cierto punto novedosos, la realidad es que sus orígenes se remontan a hace varias décadas, y que la visión que de estos conceptos se tenga puede estar distorsionada por su extensiva utilización por ámbitos como la prensa o el cine.

Existen múltiples definiciones de lo que puede entenderse por inteligencia artificial. Una de las más intuitivas es quizá la de capacidad de construir una máquina que se comporte de manera que, si el mismo comportamiento lo realizara un humano, este sería considerado inteligente. Como podrá observarse, la definición anterior admite, a su vez, dentro de ella diferentes acepciones en función de las tareas que realicen estos sistemas. Así, dentro de inteligencia artificial podrá haber sistemas que busquen imitar el pensamiento humano, como sería el caso de las redes neuronales; sistemas que busquen realizar actuaciones que sigan una lógica racional, como son los sistemas expertos; sistemas que emulen el comportamiento humano, como los robots o aquellos otros $D$ 
que reproduzcan comportamientos racionales, como los agentes inteligentes.

Los orígenes de estos desarrollos están lejos de ser contemporáneos. Así, existe un cierto consenso a la hora de considerar 1956 como la fecha de nacimiento de la inteligencia artificial, al pronunciarse por primera vez este término por John McCarthy, aunque la inteligencia artificial de este modo considerada no habría sido posible de no existir desarrollos previos tan anteriores que pueden datarse en 1869.

Existe una multiplicidad de términos relacionados con la inteligencia artificial y que de manera natural han traspasado el plano más técnico hacia una considerable mayoría social. No es objeto del presente artículo profundizar en los mismos, pero sí se considera necesario definir de manera somera aquellos que aparecerán a lo largo del texto para una mejor comprensión del mismo. Así, nos referiremos a machine learning como rama de la inteligencia artificial que permite que los sistemas aprendan de manera automática, siendo capaces de identificar patrones y tomar decisiones de manera autónoma o al menos con la mínima intervención humana. Un paso más avanzado del machine learning daría lugar al deep learning, en el que los propios sistemas, sin intervención humana, son capaces de procesar los datos de manera semejante a un ser humano y extraer conclusiones. A un lado de ambos procesos nos encontraríamos con técnicas como el text mining, tecnologías que son capaces de explorar de forma ágil grandes volúmenes de texto, automática o semiautomáticamente, descubriendo los patrones, tendencias o reglas, con el fin de extraer de manera sencilla el conocimiento. En la base de todo ello, y como pieza fundamental de todo lo anterior, se encontraría el concepto de algoritmo, pudiendo definirse de una manera tan simple como una secuencia de operaciones definidas que bien implementadas consiguen la obtención de un resultado esperado.

Habiendo ya sentado los conceptos básicos, resulta evidente que las Administraciones públicas no pueden ni deben quedarse al margen de estos desarrollos. Desde una perspectiva general, los beneficios para el ámbito público que pueden derivarse de una correcta inversión e impulso de estas técnicas abarcan desde la agilidad en la realización de trámites para el ciudadano con una mejora de resultados y utilización de menores recursos, a través de la automatización de procesos; el apoyo a la toma de decisiones y realización de políticas públicas más apegadas a la realidad a través de los análisis automatizados de grandes volúmenes de datos; hasta una mejora en la relación con los ciudadanos, por ejemplo, a través de la utilización de agentes virtuales.

El ámbito que nos ocupa, el de la defensa de la competencia, es por definición más estrecho que lo hasta ahora descrito, pero no por ello la utilización de estas técnicas resulta más limitada, como se verá en el apartado 4. Sin embargo, previo a señalar las potencialidades ya reales que estas técnicas tienen en competencia, concretamente en las aplicadas por la CNMC, cabe detenerse en los problemas y riesgos que la mayor digitalización y utilización de herramientas derivadas de la inteligencia artificial, como los algoritmos, pueden tener para la competencia.

\section{Riesgos de la inteligencia artificial desde el punto de vista de la competencia}

Los algoritmos se pueden caracterizar como impulsores tecnológicos de la digitalización $\triangleright$ 
y desde luego no hay duda acerca de los importantes efectos positivos que generan. Muchos procesos rutinarios, como enviar emails, sacar fotos, encontrar una ubicación y saber cómo llegar a ella, se basan en el uso de algoritmos. Muchos modelos de negocio innovadores y potenciadores del bienestar de la sociedad no existirían en ausencia de algoritmos.

Una de las herramientas más conocidas y utilizadas que proporciona la inteligencia artificial son los sistemas de recomendación. Son algoritmos que intentan predecir los próximos ítems (productos, canciones...) que cada individuo querrá consumir en base a sus preferencias e intereses, personalizando al máximo lo que ofrecen a cada usuario. Estos sistemas se pueden construir gracias a la cantidad de información individual que las distintas aplicaciones recaban de las personas. Toda esta información nutre a los algoritmos y les permite aprender de los gustos de los usuarios y recomendarles lo que realmente les interesa. Si los algoritmos aciertan, logran que los usuarios pasen más tiempo en las plataformas y que visualicen más publicidad o realicen más compras.

Estos sistemas son tan efectivos que todos los días recibimos recomendaciones y «productos relacionados» aconsejados por distintas aplicaciones y webs. Entre los más conocidos están los algoritmos de recomendación de Neftlix, Spotify, Amazon, Google o Facebook. Mediante estos sistemas Neftlix nos sugiere películas y series, Spotify nos recomienda canciones y artistas, Amazon nos ofrece productos de venta cruzada, Google nos proporciona búsquedas en línea o Facebook nos recomienda amistades. Por ejemplo, en el caso de Amazon, los sistemas de recomendación generan «clientes que compraron esto, también compraron...». El sistema de recomendación actúa como un vendedor hipereficiente que, teniendo en cuenta los gustos y necesidades del usuario, es capaz de realizarle recomendaciones totalmente personalizadas en un breve instante. Precisamente, un porcentaje considerable de las ganancias de Amazon proviene de estos sistemas de recomendación.

Los algoritmos también se pueden utilizar para determinar los precios de una empresa. Con estos algoritmos las empresas pueden monitorizar los precios de sus competidores y en base a esta información y a los propios costes de la empresa, su capacidad productiva, las características del mercado y la situación de la demanda, actualizar de manera dinámica sus precios. Se puede distinguir entre algoritmos que implementan reglas muy sencillas, como, por ejemplo, seleccionar el menor precio de los competidores, o bien algoritmos mucho más complejos que experimentan con distintas estrategias y aprenden, como lo haría el cerebro humano, a determinar los mejores precios para la empresa aplicando técnicas de deep learning. Estos algoritmos los puede desarrollar la propia empresa que los utiliza o bien empresas especializadas que se dedican a la comercialización de este tipo de software de precios. Su uso está tan extendido en el comercio electrónico que ya en el año 2017 un informe de la Comisión Europea ${ }^{1}$ relativo al comercio online concluyó que dos tercios de los distribuidores online usaban software automático para ajustar sus propios precios a los precios observados de sus competidores.

La utilización de algoritmos para personalizar servicios o mejorar los modelos de fijación de precios puede generar eficiencias que benefician tanto a las empresas como a los $D$

Final report on the E-commerce Sector Inquiry. Report from the Commission to the Council and the European Parliament. 
consumidores en términos de bienes y servicios nuevos, mejores y más personalizados. Sin embargo, el uso cada vez más extendido de los algoritmos puede derivar también en comportamientos anticompetitivos, al favorecer que las empresas se coordinen sin necesidad de un acuerdo formal o bien que los algoritmos decidan por sí mismos cooperar para limitar la competencia sin necesidad de interacción humana.

A los algoritmos que fijan los precios en el comercio online no se les enseña necesariamente a coludir (cuando dos o más agentes se ponen de acuerdo para restringir la competencia y aumentar sus ganancias conjuntas), no obstante, estos programas, que están diseñados para favorecer al vendedor, pueden aprender sistemáticamente a jugar sofisticadas estrategias colusivas y deducir por sí mismos que pactar precios es más eficiente que competir para conseguir mayores beneficios (Calvano, Calzolari, Denicolò y Pastorello, 2020).

Los algoritmos pueden facilitar la colusión de distintas maneras. En primer lugar, se pueden utilizar para monitorizar a los competidores, o, en su caso, los precios de los distribuidores online ${ }^{2}$, y hacer cumplir una estrategia coordinada ya establecida. Esta monitorización favorece una mayor estabilidad y efectividad de los acuerdos, puesto que las posibles desviaciones del acuerdo se detectan con rapidez y además se minimizan los contactos entre las partes y, como consecuencia, el riesgo de ser detectados por las autoridades de competencia. Este caso necesita una comunicación explícita entre las empresas para constituir el cártel y posteriormente el uso de un algoritmo para monitorizar el acuerdo alcanzado. De

2 http://ec.europa.eu/competition/antitrust/cases/dec_ docs/40465/40465_337_3.pdf manera que las autoridades de competencia podrían detectar este tipo de colusión con las herramientas tradicionales disponibles, puesto que el algoritmo se utiliza solo como un facilitador del acuerdo ya alcanzado entre las partes.

En segundo lugar, puede suceder que varias empresas recurran a la misma empresa de software para que desarrolle su algoritmo de precios. Esto podría crear un marco hub and spoke (Ezrachi y Stucke, 2015) en el que los competidores utilizan el mismo hub para diseñar sus algoritmos, lo cual deriva en el uso del mismo algoritmo o versiones muy similares para la fijación de precios, facilitando un comportamiento coordinado por parte de las empresas que están utilizando el mismo «cerebro» (OECD, 2017) para seleccionar su estrategia de precios. En este caso, si los competidores se ponen de acuerdo para adquirir sus algoritmos dinámicos de fijación de precios a la misma empresa de software y además exigir que estos algoritmos se programen para no competir entre ellos, estaríamos de nuevo ante un caso de coordinación explícita y una inequívoca violación de las reglas de competencia. No obstante, si los competidores, sin necesidad de interacción entre ellos, deciden utilizar el mismo hub para el desarrollo de sus algoritmos de precios y terminan usando los mismos algoritmos o muy similares, nos podríamos encontrar ante una situación de coordinación tácita. Hay que observar que el efecto de recurrir a la misma empresa de software se intensifica cuando las empresas utilizan además el mismo conjunto de datos para nutrir a su algoritmo, porque ello permite que el precio cartelizador alcanzado por el algoritmo sea más rentable para las empresas que lo utilizan.

Una tercera posibilidad es la de favorecer que el mercado sea más predecible. Para ello las empresas disponen de sus propios $D$ 
mecanismos para establecer los precios, pero reaccionan de manera predecible ante factores externos, y este comportamiento puede ser detectado por otros agentes, enviándose así una invitación a coludir.

La última posibilidad sería aquella en la que los competidores diseñarían de manera unilateral sus algoritmos de fijación de precios seleccionando un determinado objetivo, como puede ser la maximización del beneficio, y aplicarían técnicas complejas de deep learning. Estos algoritmos determinarían cuál es la estrategia óptima de fijación de precios, pudiendo llegar de manera autónoma a la conclusión de que la mejor táctica es coludir. En estos casos el principal problema para las autoridades de competencia es que el algoritmo va tomando decisiones sin revelar información sobre el proceso seguido, de manera que, por ejemplo, si se observa un incremento de los beneficios, no se puede diferenciar si es debido a un aumento en el número de consumidores, a una coordinación tácita o bien a otra causa. En estas ocasiones se estaría ante una «caja negra» que hay que analizar para poder determinar si realmente se está ante un caso de colusión.

A pesar de los beneficios que genera la inteligencia artificial, detallados previamente, hay una creciente literatura sobre política de competencia que fija el foco en los posibles riesgos que la inteligencia artificial genera a los consumidores. Las principales teorías del daño hacen referencia a la posibilidad de que el uso de algoritmos de precios derive en casos de colusión algorítmica y como consecuencia los consumidores paguen precios superiores a los que pagarían en un mercado competitivo; por otra parte estaría la tendencia a la hiperpersonalización generada por algunos sistemas de recomendación, en la medida que cuando un individuo busca un determinado producto, los algoritmos le pueden derivar a un único proveedor del mismo sin siquiera mencionar al resto de competidores y también la aparición de nuevas barreras de entrada vinculadas a la inteligencia artificial, entre otras, el acceso a datos.

En relación con la colusión algorítmica hay que observar que, aunque su existencia es una realidad demostrada teórica y empíricamente, la detección de este tipo de ilícitos es relativamente compleja para las autoridades de competencia, y por el momento no hay muchos casos sancionados. En el ámbito europeo se podrían destacar dos de los primeros expedientes sancionados. Por una parte está el cártel de venta online de pósteres sancionado por la autoridad de competencia británica, la Competition and Markets Authority (CMA), en el año 2016. En esta ocasión las partes habían acordado no rebajar los precios de los posters vendidos en la web de Amazon en Reino Unido, y para poder implementar el acuerdo se utilizaba un software de ajuste de precios. Por otra parte, un caso sancionado por la Comisión Europea en el año 2018 relativo a cuatro fabricantes de productos electrónicos que imponían precios de reventa a sus distribuidores online. La Comisión enfatizó que las compañías habían usado algoritmos sofisticados para monitorizar el precio fijado por los distribuidores, permitiéndoles intervenir rápidamente en el caso de una reducción de los precios.

Por su parte, la autoridad de competencia española, la CNMC, incoó un expediente sancionador en el año 2020 por posibles prácticas restrictivas de la competencia en el mercado de la intermediación inmobiliaria ${ }^{3}$. Estas prácticas consistirían en la coordinación de precios y otras condiciones comerciales por parte de $\triangleright$

\footnotetext{
3 Este caso está en fase de instrucción: https://www.cnmc.es/ la-cnmc-inicia-un-expediente-sancionador-contra-siete-empresasvinculadas-al-mercado-de-379303
} 
intermediarios inmobiliarios, estando la coordinación instrumentada, entre otros medios, a través del uso de software y de plataformas informáticas, y habría sido facilitada por empresas especializadas en soluciones informáticas a través del diseño del programa informático de gestión inmobiliaria y de sus algoritmos.

Hasta el momento, en estos casos sancionados, los algoritmos se han utilizado para ejecutar o facilitar un acuerdo explícito entre competidores concertado previamente, por ello su detección se ha podido realizar utilizando las herramientas tradicionales con las que cuentan las autoridades de competencia. No obstante, la creciente sofisticación de los algoritmos con una mayor recurrencia a las técnicas de IA dificulta la identificación y detección de casos de colusión algorítmica. Cuando la colusión la incentivan humanos, existe algún tipo de comunicación para acordar los términos de la coordinación que puede ser detectada por las autoridades de competencia y utilizada como prueba, sin embargo, cuando la colusión deriva de la interacción de algoritmos no necesariamente programados para coludir, estas comunicaciones no están presentes y su detección se complica. En esta última situación la violación de las reglas de competencia se refleja únicamente en la existencia de resultados colusivos en el mercado.

Algunas autoridades de competencia consideran que las herramientas disponibles puede que no sean del todo adecuadas para tratar de manera eficiente con los algoritmos de precios y que podría ser necesario incluir alguna referencia a la colusión tácita facilitada por los algoritmos de precios en la tipificación de las conductas colusorias prohibidas ${ }^{4}$. En el ámbito

4 Como afirma el antiguo presidente de la autoridad británica de competencia, David Currie, que se cuestionaba si las herramientas legales disponibles son capaces de hacer frente a los retos derivados del académico se están analizando las condiciones de mercado que facilitan este tipo de prácticas colusivas derivadas del uso de algoritmos de precios, las posibles implicaciones que tienen en la política de competencia y las posibles soluciones para hacerles frente. Se pueden destacar las recomendaciones de una serie de artículos recientes sobre este tema, como el publicado por Calvano, Calzolari, Denicolò, Harrington y Pastorello en noviembre de 2020, en el que aconsejan a las autoridades de competencia que los algoritmos de precios de las empresas sean auditados y testados en entornos controlados para que se puedan simular todos los tipos de posibles desviaciones de los precios existentes y se observe la reacción de los algoritmos en ausencia de factores de confusión. Asimismo, plantean como opción que se considere a las empresas legalmente responsables de las reglas de precios que sus algoritmos de aprendizaje adoptan, puesto que así las empresas se verían incentivadas a evitar la colusión mediante una monitorización rutinaria de los resultados de sus algoritmos. Rab (2019) considera fundamental el conocimiento, a nivel tecnológico, de los algoritmos y cómo operan y recomienda que se descarten hipótesis alternativas relativas a las características del mercado que puedan facilitar o evitar la coordinación antes de realizar cambios a nivel político y legal. Por su parte, Ershov, en su artículo sobre algoritmos de precios y competencia en el mercado de la gasolina en Alemania (Assad, Clark, Ershov y Xu, 2020), observa que el incremento de la colusión tácita como consecuencia del uso de los algoritmos de $\triangle$

ascenso de la economía del algoritmo, como, por ejemplo, los generados por los algoritmos que aprenden por sí mismos. En Rab (2019). https:// www.researchgate.net/publication/338905751_Artificial_intelligence_ algorithms_and_antitrust). 
precios podría potenciar que se cambiase la condición jurídica de esta forma de colusión.

Adicionalmente a los riesgos generados por los algoritmos de precios, el mayor uso de la inteligencia artificial puede generar nuevas barreras de entrada, entre otras, el acceso a los datos ${ }^{5}$. Los datos son un elemento esencial de la inteligencia artificial puesto que son el input con el que se nutren los algoritmos. La habilidad de los algoritmos a la hora de detectar patrones y relaciones depende de la calidad, cantidad y variedad de los datos que se utilicen. Proporcionar pocos datos o incorrectos a la hora de entrenar a los algoritmos deriva en un mal funcionamiento de los mismos, la generación de sesgos y, como consecuencia, la posibilidad de extraer conclusiones falsas a partir de los resultados generados. Por ello, prácticas excluyentes por parte de algunas empresas para limitar a sus competidores el acceso a los datos pueden derivar en barreras de entrada ${ }^{6}$. En concreto, en el caso de los datos, nos encontramos ya con una estructura en la que la competencia está muy debilitada, dado que el valor y la utilidad de los mismos crecen de manera exponencial con el volumen de datos tratados, lo cual está dando una importante ventaja a los grandes operadores establecidos y sugiere una tendencia a la concentración del mercado ${ }^{7}$. Un nuevo entrante se enfrenta a grandes dificultades a la hora de adquirir datos, ya que para poder disponer de una copia mínima de los datos disponibles por los incumbentes tendría

\footnotetext{
5 https://www.cnmc.es/prensa/cnmc-acco-contribucion-libroblanco-inteligencia-artificial-CE-20200930

6 Como se identifica en la contribución de la CNMC a la conferencia organizada por la Comisión Europea sobre Shaping competition policy in the era of digitisation en enero de 2019 (https://ec.europa.eu/competition/ scp19/media_en.html\#Contributions).

Como se detalla en la contribución de la CNMC a la mesa redonda organizada por la OCDE sobre Consumer data rights and competition en junio de 2020 (http://www.oecd.org/daf/competition/consumer-data-rightsand-competition.htm).
}

que pedir autorización permanente como consecuencia del reglamento de protección de datos.

\section{Oportunidades de la inteligencia artificial para la competencia. La experiencia de la CNMC}

La presencia de los anteriores riesgos, sin dejar de ser importantes, no puede conducir a renunciar a las grandes posibilidades que se derivan de la aplicación de la inteligencia artificial y otras técnicas estadístico-econométricas en el campo de la competencia y que en el momento actual se encuentran en mayor o menor grado de implementación por parte de la CNMC.

Fueron varias las razones por las cuales la CNMC empezó a considerar necesario un impulso a esta materia en el seno de la institución. En primer lugar, la constatación de la presencia cada vez más importante de datos en fuentes abiertas con amplias potencialidades, tanto en materia, por ejemplo, de soporte de cara a la obtención de información ante inspecciones como, muy señaladamente, en el ámbito de la contratación pública de cara a la detección de casos de bid rigging o colusión en licitaciones. Esta cuestión, en conjunción con un notable desarrollo de las aplicaciones y herramientas de tratamiento de datos, amplía de importante manera las posibilidades de detección de ilícitos de competencia.

Por otro lado, y aunque de tremenda utilidad, las características inherentes a los programas de clemencia, como puede ser el hecho de tratarse de actuaciones más reactivas que proactivas de las autoridades de competencia, así como la imposibilidad ante lo anterior de realizar una priorización entre mercados o sectores, empujan a la búsqueda de nuevas $\triangleright$ 
actuaciones de oficio en las cuales la aplicación de estas nuevas técnicas puede desempeñar un papel fundamental. Asimismo, la mera posibilidad de que exista esta detección de oficio tendrá un efecto desincentivador en la formación de los cárteles.

Por último, la comprobación de la tendencia internacional al respecto, con la creación de unidades de inteligencia con competencias con mayor o menor intensidad en materia de aplicación de inteligencia artificial, por parte de autoridades nacionales de competencia de nuestro entorno (entre otras, la Data and Digital Insights Unit de la Competition and Markets Authority de Reino Unido, la Digital Economy Unit de la Autorité de la Concurrence francesa, o la unidad de inteligencia de mercados de la Comisión Federal de Competencia Económica mexicana), concluye en la creación de manera efectiva de la Unidad de Inteligencia Económica (UIE) adscrita a la Dirección de Competencia de la CNMC en el año 2018.

La UIE, formada por perfiles económicos, jurídicos, estadísticos, matemáticos e informáticos, con amplia experiencia en materia de competencia, se erige como la unidad de la CNMC encargada de aplicar técnicas estadísticas avanzadas e inteligencia artificial para mejorar la detección de oficio de prácticas anticompetitivas.

Además, la UIE da soporte a la toma de decisiones de la Dirección de Competencia gracias al análisis de datos a través de herramientas de bussiness intelligence, así como la mejora de la efectividad de las inspecciones, por ejemplo, mediante la obtención de información con técnicas OSINT (Open Source Intelligence). Adicionalmente, analiza comportamientos derivados de esta nueva realidad, como es la colusión algorítmica descrita en el apartado precedente.
Por último, la UIE es la unidad de la CNMC encargada del programa de informantes de ilícitos de competencia, para lo cual cuenta con diferentes vías de colaboración ciudadana anónima que le permiten tener conocimiento de indicios de prácticas anticompetitivas manteniendo en todo momento el anonimato y la confidencialidad de dicha colaboración.

Centrándonos dentro de estas funciones asignadas en la del análisis de datos tanto para el reforzamiento de expedientes provenientes de cualquier origen, como pudieran ser solicitudes de clemencia o denuncias, como de aquellos realizados de oficio, la obtención de datos adquiere un papel preeminente y previo a la aplicación de cualquier técnica estadístico-econométrica o de inteligencia artificial.

En relación con estas fuentes, y sin ánimo de exhaustividad, cabe reseñar la obtención de información a través de informantes, la colaboración interadministrativa y con fuerzas y cuerpos de seguridad del Estado, así como la búsqueda a través de diferentes herramientas específicamente orientadas para la obtención de información en fuentes abiertas de una manera más ágil y focalizada. Sin embargo, ha de destacarse entre todas ellas el papel fundamental que para la detección de casos de bid rigging desempeñan los datos de contratación pública generalmente, pero no solo, alojados en la Plataforma de Contratación del Sector Público. La descarga de estos datos de carácter público por parte de la CNMC no resulta novedosa, habiendo comenzado en 2015, sin embargo, la calidad y cantidad de los datos en ella alojada ha experimentado una notable mejora desde entonces gracias, entre otras cuestiones, a la promulgación de la Ley 9/2017, de 8 de noviembre, de Contratos del Sector Público; la potencial utilización de los mismos por parte de esta Comisión se ha visto notablemente incrementada. 
De este modo, la CNMC construye su propia base de datos de contratación pública a partir de la descarga seleccionada de determinados datos de dicha plataforma, a la que se realiza un conveniente proceso automatizado de filtrado y limpieza de errores manifiestos, así como categorización de los datos por niveles de calidad. Este paso, que pudiera ser considerado de menor importancia, deviene en fundamental para poder obtener resultados válidos a la hora de realizar un tratamiento globalizado de los datos.

Esta información es, a su vez, completada con información de otras fuentes, entre otras cuestiones y para casos seleccionados, la derivada de la aplicación por parte de la UIE de procesos de text mining sobre información no estructurada de licitaciones.

Una vez realizados estos procesos para con los datos, el abanico de herramientas disponibles para el tratamiento de la información es amplio, pasando desde técnicas estadísticas, como cuadros sunburst o rayos de sol o gráficos de diagramas radiales que ordenados por características permiten una visualización más ágil de la información y la detección de la posible presencia de patrones compartidos entre empresas, hasta desarrollos más sofisticados que impliquen inteligencia artificial.

Más allá de lo anterior, la CNMC ya aplica, de manera incipiente por el momento, nuevas técnicas de detección de comportamientos anticompetitivos a partir de inteligencia artificial. Este es el caso, por ejemplo, de la aplicación de técnicas de análisis de redes a datos de contratación pública que permiten identificar y mostrar determinadas pautas o patrones en las formas de vinculación entre empresas que pueden derivarse del comportamiento de un cártel.

La aplicación de estas técnicas abarca diferentes tipos, con el fin de que la evidencia en su caso encontrada sobre los datos sea más robusta y quede contrastada. Por un lado, $D$

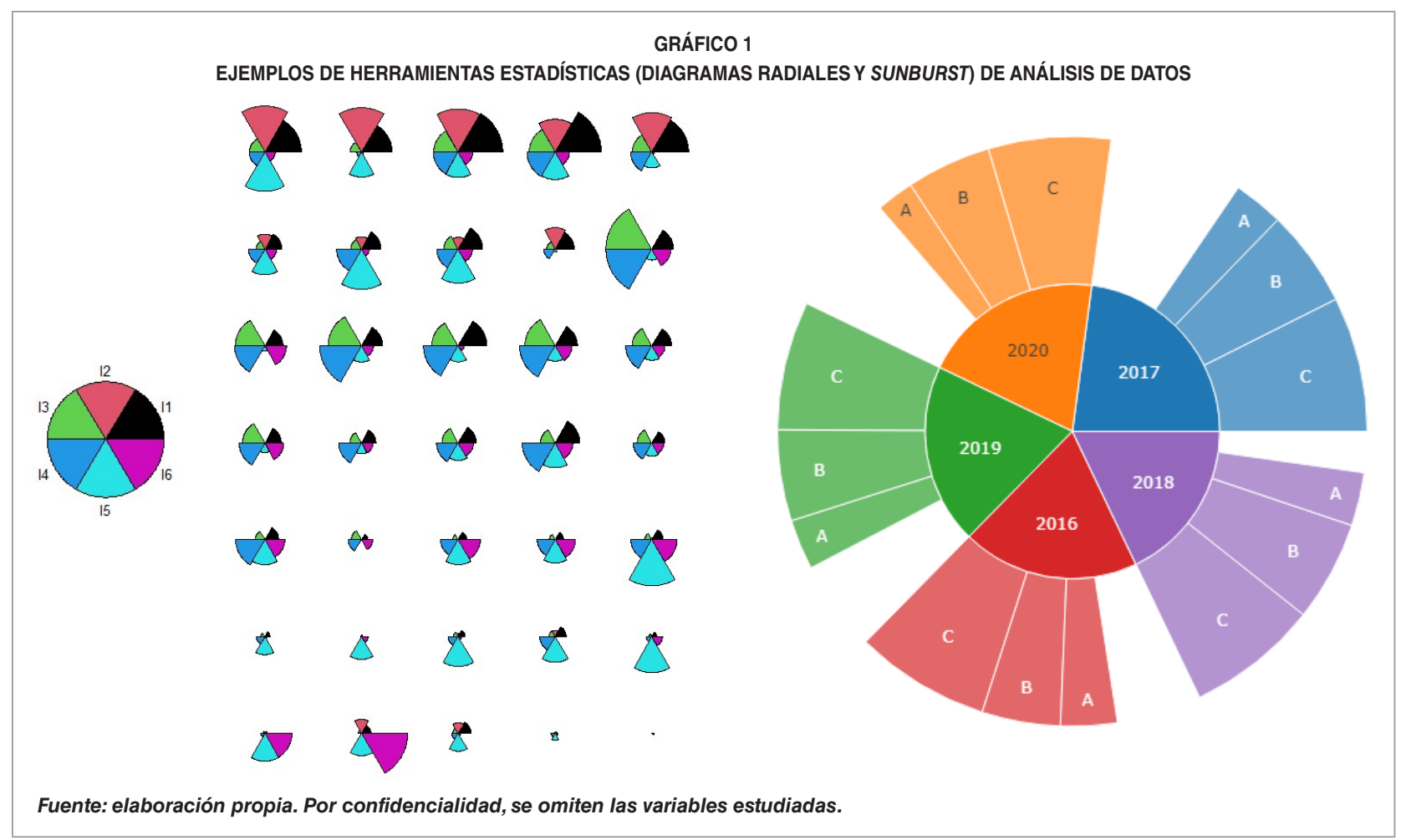




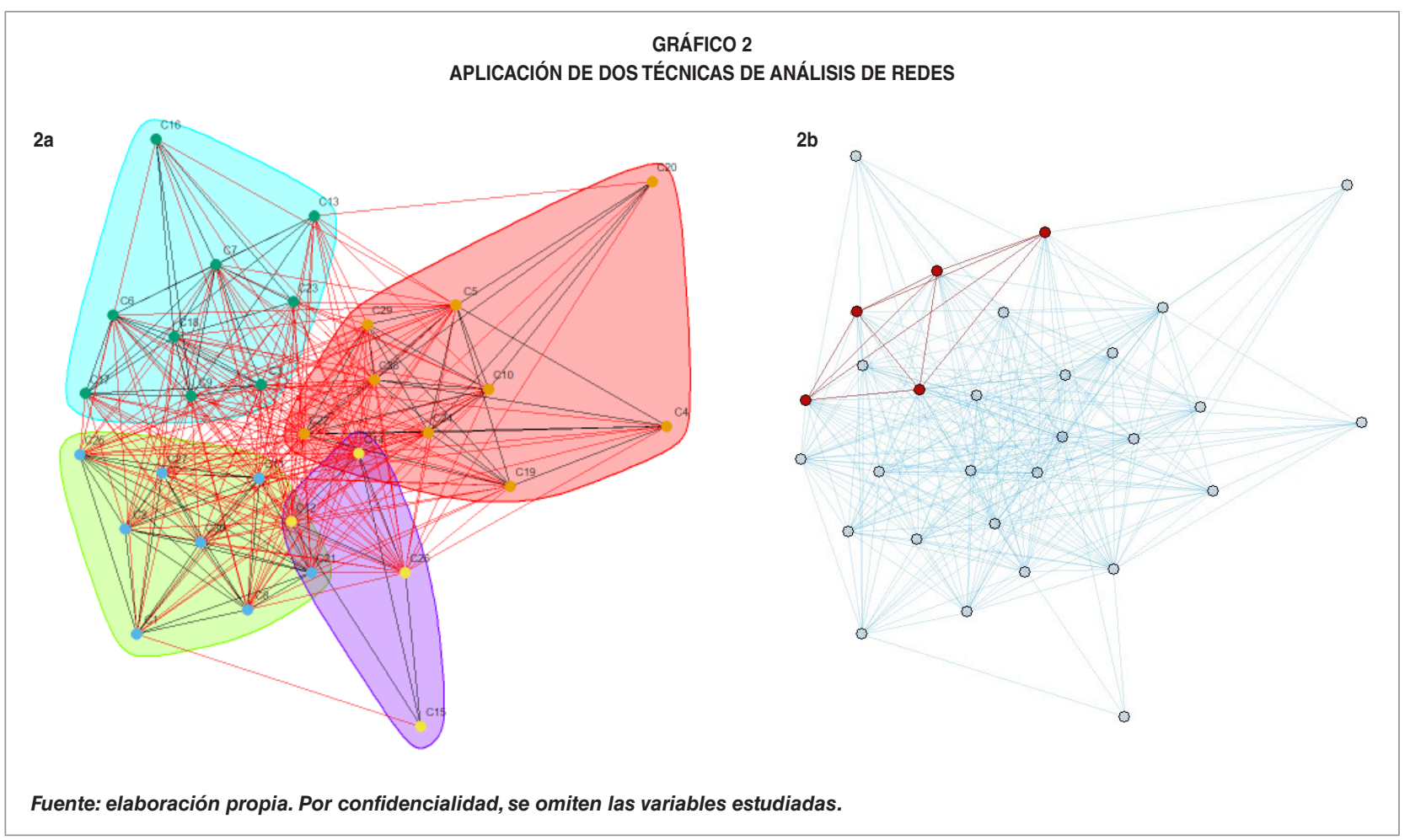

se aplicarían técnicas de aprendizaje no supervisado que busquen clústeres de empresas, como se aprecia en el Gráfico 2a, en el que se mostrarían aquellas empresas que de acuerdo con esta técnica serían más propensas a formar parte de un cártel.

Por otro, con otras técnicas de análisis de redes (Gráfico $2 b$ ) se buscarían aquellos grupos de empresas que se considera que, acorde a unas determinadas variables, serían susceptibles de encontrarse en un mismo clúster o grupo, a través de la búsqueda de nodos densamente interconectados en comparación con el resto de la red. Las variables tenidas en cuenta pueden ser diferentes, todas ellas internacionalmente aceptadas como banderas rojas en la detección de casos de bid rigging.

Otras técnicas utilizadas por la UIE pasan por la aplicación de diferentes métodos de machine learning para la obtención de indicadores de riesgo de bid rigging que completen otros ya disponibles en la unidad.
Por último, se aplican otras técnicas en las que, a diferencia del análisis de redes, a través del uso de algoritmos se buscarían patrones de ilícitos de competencia determinados, como pudiera ser el reparto de lotes dentro de una licitación, para lo que posteriormente se descartaría que el resultado pudiera provenir de la estructura del mercado o de una deficiente redacción de los pliegos.

En todo caso, cabe advertir que la aplicación de todas estas técnicas se realiza de manera aproximativa al caso, sobre todo en lo que a detección de oficio se refiere, y resulta de gran utilidad a la hora de poder advertir a través del conjunto de datos qué sectores o mercados deberían ser analizados con mayor detenimiento. No debe, por tanto, inferirse de lo anterior la apertura directa de un procedimiento sancionador con el único soporte de estas técnicas ni que las mismas se utilicen como remplazo de la supervisión humana realizada por el personal de la Comisión Nacional de $\square$ 
los Mercados y la Competencia. Sin embargo, el momento presente se considera ampliamente oportuno en lo que a detección de bid rigging se refiere, habida cuenta del papel que en los próximos años tendrá la contratación pública derivada de los fondos europeos Next Generation, momento en el que serán de gran utilidad las técnicas presentadas.

\section{Conclusión}

Los desarrollos en materia de inteligencia artificial han llegado para quedarse e incluso para ser superados continuamente en un futuro cercano. Esto no hace sino reforzar la necesidad de que las Administraciones públicas, en modo general, y las autoridades de competencia, en particular, adapten sus organigramas y perfiles orientados, por un lado, al aprovechamiento de estos desarrollos y, por otro, a la vigilancia de los comportamientos que de estas nuevas realidades pueden derivarse.

El ámbito de defensa de la competencia no escapa a la progresiva permeabilidad de la inteligencia artificial en todas sus facetas, observándose riesgos, pero también posibles ventajas de la presencia de estos desarrollos.

En relación con los primeros se podrían destacar los siguientes: en primer lugar, la posibilidad de un incremento en el número de casos de colusión algorítmica como consecuencia de la mayor frecuencia de uso de los algoritmos de precios; en segundo lugar, la posible exclusión de competidores generada por determinados sistemas de recomendación con tendencia a la hiperpersonalización con recomendaciones exclusivas a un único proveedor; $y$, en tercer lugar, la aparición de nuevas barreras de entrada vinculadas a la inteligencia artificial, entre otras, el acceso a datos.
A pesar de todo ello, deben considerarse todos estos desarrollos como de una amplia potencialidad para con las competencias que las autoridades de competencia tienen asignadas. Así, mediante la creación de unidades ad hoc con perfiles específicos, como el caso de la UIE en la CNMC, el aprovechamiento de estos nuevos recursos es cada día más una realidad.

En primer lugar, y aun sin tener que recurrir a desarrollos de inteligencia artificial, la implementación de técnicas estadístico-econométricas más depuradas permite realizar una aproximación más visual y ágil al análisis de datos, sin tener que circunscribirse estos a una detección de oficio. Del mismo modo, la utilización de nuevas herramientas de búsqueda de información en fuentes abiertas refuerza y mejora las actuaciones diarias de la Dirección de Competencia de la CNMC.

Sin embargo, es en el área de la detección de oficio donde las potencialidades de la aplicación de inteligencia artificial adquieren su mayor exponente al permitir encontrar mercados, sectores o empresas donde se requeriría un análisis más en profundidad. Diferentes técnicas de análisis de redes permiten encontrar grupos de empresas que, en base a determinados parámetros, tienen una probabilidad mayor de formar parte de un cártel. Por otro lado, la utilización de determinados algoritmos posibilita detectar ilícitos concretos de competencia, como pudieran ser determinados casos de bid rigging. En la base de todo ello, técnicas de machine learning y algoritmos específicos permiten extraer información de fuentes no estructuradas. En todo caso, conviene aclarar que la aplicación de estas técnicas no presupone la apertura de un procedimiento sancionador ni su resultado, ni automatiza la toma de decisiones en ningún caso. 
En definitiva, son importantes los riesgos que en materia de competencia pueden conllevar los desarrollos en materia de inteligencia artificial, pero en todo caso será tarea de las autoridades de competencia ser capaces de aprovechar las ventajas que también de los mismos se derivan.

\section{Bibliografía}

Assad, S., Clark, R., Ershov, D., y Xu, L. (2020). Algorithmic Pricing and Competition: Empirical Evidence from the German Retail Gasoline Market (CESifo Working Paper No. 8521). https:// ssrn.com/abstract $=3682021$

BBVA (2017). Infografía: Inteligencia Artificial. https://www.bbva.com/es/infografia-inteligenciaartificial/

Calvano, E., Calzolari, G., Denicolò, V., y Pastorello, S. (2020). Al, Algorithmic pricing and Collusion. American Economic Review, 110(10), 326797. https://www.aeaweb.org/articles?id=10.1257/ aer.20190623

Calvano, E., Calzolari, G., Denicolò, V., Harrington J., y Pastorello, S. (2020). Protecting consumers from collusive prices due to Al. Science, 370 (6520), 1040-1042. Policy Forum. Technology and Law. https://science.sciencemag.org/ content/370/6520/1040
CNMC (2019). Contribución a la conferencia organizada por la Comisión Europea sobre «Shaping competition policy in the era of digitisation». https://ec.europa.eu/competition/information/ digitisation_2018/contributions/comision_nacional_de_los_mercados_y_la_competencia.pdf

CNMC (2020). Contribución a la consulta del Libro Blanco de Inteligencia Artificial planteada por la Comisión Europea. https://www.cnmc.es/prensa/cnmc-acco-contribucion-libro-blancointeligencia-artificial-CE-20200930

CNMC (2020). Contribución a la mesa redonda organizada por la OCDE sobre Consumer data rights and competition. http://www.oecd.org/daf/ competition/consumer-data-rights-and-competition.htm

Ezrachi, A., y Stucke, M.E. (2017). Artificial Intelligence \& Collusion: When Computers linhibit Competition. University of Illinois Law Review, 2017. https://papers.ssrn.com/sol3/papers.cfm? abstract_id=2591874

OECD (2017). Algorithms and Collusion: Competition Policy in the Digital Age. http://www.oecd. org/competition/algorithms-collusion-competition-policy-in-the-digital-age.htm

Rab, S. (2019). Artificial intelligence, algorithms and antitrust. Competition Law Journal, 18 (4), 141150. https://www.researchgate.net/publication/ 338905751_Artificial_intelligence_algorithms_ and_antitrust 
